\title{
The Prevalence of Prostitution in Fiji: Its Socio-economic Impact
}

\section{Rosalie R Muertigue*, Sandhiya Gounder and Kamala Naiker}

Department of Social Studies, University of Fiji, Fiji

\begin{abstract}
Prostitution has been a long time problem in most developing countries like Fiji. This paper examines the problem of prostitution in Fiji and its socio-economic impact. It also aims to present a bigger picture in which the proliferation of prostitution is not only increasing, but there are various problems that have come up with this practice such as the risk of contracting sexually transmitted infections including HIV and violence against sex worker. The researcher discusses some few programmes and policies that will help reduce the problem of prostitution. This study employs a cross-sectional method. A face-to-face interview was conducted to 10 female participants in Nadi and Lautoka using the snowball sampling. An analysis of existing documents related to prostitution and critical review of the related literature are also utilized to gather information. Prostitution is known as the world's oldest profession and considered as an active and profitable enterprise in the middle ages. In some countries, the legal status of prostitution may vary depending on the activity. From a review of the literature, poverty is the primary reason for the increasing number of prostitutes in Fiji and prostitution will exist as long as poverty exists. Both men and women are involved in this prostitution trade. But women are the ones who are more vulnerable to prostitution compared to men. Most studies revealed that economic need is the leading factor that influences this business. Economic exchange is also practiced between the prostitute and customer, whereby the participation by concerned parties is voluntary for pleasure but the women engaged seeks payment for her service. Other causes of prostitution in Fiji are lack of access to education, adequate housing and job opportunities. In spite of the strict implementation of laws in Fiji, prostitution is still prevalent and keeps on increasing every year.
\end{abstract}

Keywords: Impact; Prevalence; Prostitution; Socio-economic

\section{Introduction}

Prostitution is known as the oldest profession in the world. There are various descriptions and definitions such as "sex worker", "escort", "hostess", "women of the night" Both men and women are engaged in sex industry. It is defined as the granting of sexual favours for monetary gain. The report of Fondation Scelles revealed that there are 40 to 42 million prostitutes in the world, $35 \%$ of them are between ages of 13 and 25 , and $80 \%$ of them are female. During the Victorean era, prostitution of women became like a luxury item (like a car) they were advertised as 'sexed bodies for hire". Prostitution has been a long time problem in Fiji, since the country became famous as tourist destination. History reveals that prostitution even started during the indentured time, some women are recruited as prostitutes. Even though it is illegal in Fiji, still widely practiced in any places in Fiji and continues to grow.STF (2013) survey shows that $33 \%$ of Fiji prostitutes are school students coming from the outer island, and they came to Suva for education. According to Fiji Sun Chief of Staff, Cheerieann Wilson, some student prostitutes in Suva charged only 5FD to 20FD for them to buy school supplies. According to the research carried out by Save the Children, the increasing number of tourists in Fiji will lead to a greater chance of sexual exploitation among women [1]. This research study was undertaken primarily to examine the prevalence of prostitution in Fiji by the use of primary data and secondary data. The study aims to map a profile of women in the involvement of prostitution including the existing discourse on the economic and social root causes, and operations that contribute to the proliferation of the issue. The researcher interviewed 10 female participants from Nadi and Lautoka with the use of both structured and unstructured questionnaire to gather data. Nadi is the famous tourist destination in Fiji where prostitutes are visible during night time. Selling of sex is illegal, however the government of Fiji is promoting tourism and employment of migrants that will contribute earnings to the government. In Thailand, tourism is a major earner of foreign exchange, providing a large number of jobs in the hotel and restaurants sector, in commercial enterprises, as well as in the commercial sex sector (TDRI, 1992). Prostitution also plays an important role in the Indonesian economy, and is a substantial contributor to government revenue. This study attempts to identify the reasons of women in engaging prostitution and determine its impact [2,3]. People from industrialized countries like to travel in third world countries to enjoy and study exotic people and nature. According to Pleumarom, international sex trade will further experience unprecedented growth, prompted by ever larger flows of people and money across borders, the burgeoning sex industry has its dark sides. But as sex is a human need and prostitution is here to stay. Some human rights advocates stressed that all prostitution involves coercion of one kind or another; therefore it should be regarded as a violation of human rights and as one of the most alienating forms of labour [4].

\section{Statement of the Problem}

This study aims to examine the prevalence of prostitution in Fiji and its socio-economic impact. Specifically, it seeks to answer the following:

1. What is the socio- demographic characteristic of the prostitute in Fiji?

2. What are the reasons for involvement in prostitution and methods of entry?

3. What is the impact of prostitution on society?

*Corresponding author: Rosalie R Muertigue, Assistant Professor, Department of Social Studies, University of Fiji, Fiji, Tel+6796640600; E-mail: rosaliep@unifiji.ac.fj

Received November 07, 2017; Accepted January 05, 2018; Published January 10, 2018

Citation: Muertigue RR, Gounder S, Naiker K (2018) The Prevalence of Prostitution in Fiji: Its Socio-economic Impact. Arts Social Sci J 9: 318. doi: 10.4172/21516200.1000318

Copyright: (c) 2018 Muertigue RR, et al. This is an open-access article distributed under the terms of the Creative Commons Attribution License, which permits unrestricted use, distribution, and reproduction in any medium, provided the original author and source are credited. 


\section{Objectives of the study}

1. To describe the socio-demographic characteristics of women involved in prostitution;

2. To determine the reasons for involvement and methods of entry;

3. To identify the impact of prostitution in the society.

\section{Methodology}

Research Locale of the study, the study was conducted in Nadi and Lautoka city last April 2017 (Figure 1).

\section{Research design}

This study employs cross-sectional method with the use of structured questionnaire. A face-to-face interview and focus group discussion is conducted to 20 female prostitutes in Nadi and Lautoka City. The purpose of utilizing this method is to describe the nature of a situation as it exists at the time of the study and to explore the cause of a potential phenomenon [5].

\section{Research instrument}

The questionnaire consists of closed questions and open-ended questions used in the study. The number of completed questionnaires received was 20, giving a response rate of $100 \%$ percent. The questionnaire consisted of three main parts: The Socio-demographic characteristics; The Reasons of Involvement and Methods of Entry; Impact of prostitution in the society [6].

\section{Respondents and sampling}

The primary data needed in this study were collected with the use of a questionnaire which was distributed and personally collected by the researcher to avoid delay and optimize the use of other resources as time availability. Using snowball sampling 20 female respondents were chosen from Nadi and Lautoka.

\section{Discussion}

Prostitution has long been existent in Fiji, with stories from way back in time when explorers first discovered the region. However, it has become a major social problem with the increased exploitation of not just women and men but also children. And with other social problems especially poverty driving people into the business, eradicating the problem has become even more difficult. According to Mr. Naupoto, prostitution is a big business with some able to earn as much as US $\$ 200$ a night. Studies stated that in sustainable prostitution paradigm, prostitution not only satisfies the customer what he wants but is also viewed as an economic development strategy for poor and marginalized women. Sex trade in Fiji provides income and employment to those directly or indirectly involved [7].

"Sustainable prostitution can significantly contribute to sustained peace in the world because sex workers and their customers are concerned with making "Love not War". And, of course, other role players who benefit from SP will also be eager to promote a peaceful and stable business climate. After all, who would want to kill the goose that lays golden eggs".

\section{Socio-demographic characteristics}

According to the results of the survey, majority come from villages and neighbouring islands of Taveuni and Labasa. Many prostitutes actually entered prostitution when they are young and remained trapped until adulthood. Young ones are highly paid than the older ones. Surprisingly, 2 respondents are still minor. They entered into prostitution at the age of 17. Majority of the respondents ranged from 18-21 years, they were generally young. This means that women are the prime of their youth when they were recruited into prostitution. As cited in the study of Rojo customers often choose girls who are lovely, energetic and sexually appealing. Ms. Malave of WeDpro, a "new girl" who still has her virginity intact bids for a high price. They decided to come to the cities as job-seekers. Unfortunately, young and innocent women are vulnerable to sex sector. One respondent came from China

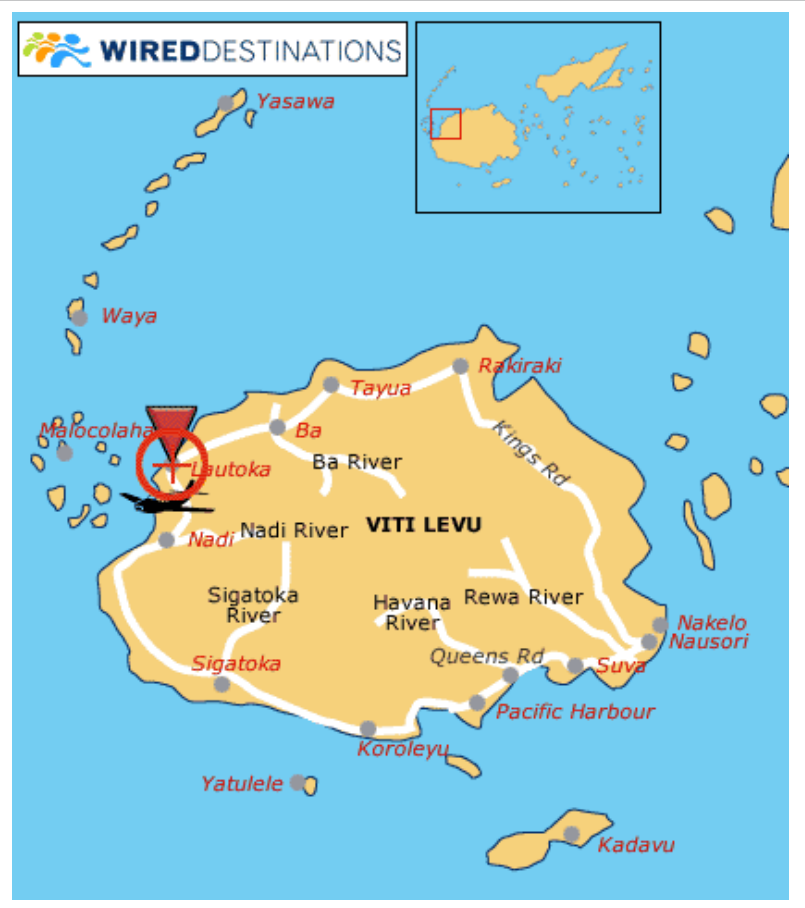

Figure 1: Present the map of the locale of the study. 
and she works as masseuse in one of the massage parlours in Nadi. This findings support to the words of Mr. Viliame Naupoto, Fijis Director of Immigration that the problem of prostitution is further enhanced by the fact that it is not just locals that are involved in the trade but also foreigners, especially foreign women, who come into Fiji under student visas but are involved in prostitution [8].

A number of the respondents had fathers who were farmers, labourers, fishermen, and thus came from poor families. Majority of the respondents were from families whose parents were not living together. About one-fourth came from broken homes and was staying with their mothers. More than half of the respondents have children. Most of these children did not live with the mother; children are looked after by the respondent's mothers.

All respondents completed elementary education and majority of them completed from 5. Surprisingly, one respondent was doing foundation courses last year in one of the universities in Lautoka. However, some respondents revealed their reasons for not completing the secondary education because their parents cannot afford to send them to school, that is why, they are force to work at an early age to help support their families. The low income background and complicated family life of these women lead to prostitution. Based on the information gathered, some respondents said their mothers knew about their job and had no choice to accept it.

\section{Reasons for involvement and methods of entry}

The primary reason is economic pressure, poverty, or insufficiency of income. Coupled with this is the desire to earn more easy money. Shamima, revealed in an interview the root causes of prostitution are low-income earning of the families, lack of education and employment opportunities. Some came from broken homes. Unpleasant experiences also pushed them to prostitution. Some respondents became prostitute to earn money to raise their children, while one respondent who works in the massage parlour was motivated by the opportunity to earn a high income. A number of women have been deprived of higher education because of financial difficulties; while some of them have had early pregnancies due to lack of sex education knowledge, therefore, they are force to leave school in order to support their child. Based on the survey results, majority of them voluntarily became prostitutes for the primary reason of supporting family members. Few respondents learnt the availability of work through an acquaintance returning to their home village, and then made their own arrangements to enter the establishment. Many studies reveal that some women in the villages desire a taste of the urban life, believing that good life can be found in the city. During the face-to-interview, one of the respondents reason in engaging in this profession is wanting to marry a foreigner in the future and have a better life. In Fiji Nadi is the number one destination of tourist visitors, the Bureau of Statistics shows that 775,239 visitors arrival per year. This data may lead also to an increase of women involved in prostitution [9].

Christine Harcourt, PhD, Research identified 25 types of sex work according to worksite, principal mode of soliciting clients, or sexual practices. These types of work are often grouped under the headings of 'direct' and 'indirect' prostitution. Based on the findings, there are three common forms of prostitution that exist in Fiji, streetwalker, escorts and massage parlour. The lowest in status are the "street-walkers" who solicit for customers in the streets and public places. Massage parlour refers to premises ostensibly dedicated to providing massage, but a range of sexual services may be provided known as "extra service".

\section{Income/Remuneration}

Research shows that women in this profession have varied incomes. The prostitute's rate will depend on some factors such as age, physical looks, ethnicity and location. Younger ones are paid more than older ones with an average income of 30FD for 30 minutes and 150 FD for overnight stay with the client. Prostitute women in Nadi charge a little bit higher compared to the women in Lautoka because the cost of living is quite expensive. The pimps are entitled to 20 percent share for every client. Women in prostitution are powerless. In most cases, prostitutes are not even involved in the transaction. It is often between a pimp and client. A prostitute becomes part of the transaction only because she will implement the terms of the transactions. The study finds out that girls in massage parlour are highly paid than streetwalkers, prices varies according to the type of service provided to the clients such as "sensation "or Masturbation job" (hand job 60 dollars, blow job 100 FD, Full service "250-300".Sohn (2016) revealed in his study that when it comes to short-term services of prostitutes, men pay most for women who are between the late teens and early twenties. Between the ages of 25 and 35, the price men are willing to pay for a prostitute drops abruptly.

\section{Impact of prostitution}

Rosales, speak out that commercialized prostitution is not the root problem but is only a symptom of the basic structural problem in society which is attributed to the imbalance of the development of the rural and urban areas, resulting in a wide disparity of access to jobs and wealth. Prostitution is strongly disapproved by a significant number of persons in community. The act is considered immoral, exploitative, and degrading of the persons involved. These women often stigmatized by society especially in Fiji which a predominantly a Christian nation since they become a threat to health due to the diseases that they might spread out like venereal diseases or AIDS. They have a low self-image. During the interview the researcher asked if they were satisfied with their job, all of them answered negatively. On the other hand, dissatisfaction arose from the unstable income and the risks of sexually transmitted disease. One respondent claimed that some of her clients don't want to use condom, so that made her worry every time she goes to the health centre for the monthly hygiene. Some respondents revealed that this job is also dangerous to their physical well being especially when they had to deal with sadistic and drunk customers. They also experienced health problems like lack of sleep, irregular eating habits and the greatest fear was contacting venereal disease. Almost all of them have the desire to leave the job; they also wished to get married, get another job or save money and have their own house. Drawing the positive effects of prostitution from the study of Kangiwa, prostitution satisfies the sexual needs of some men who are temporarily separated from their wives or normal regular partners or lovers. Women in this industry are considered as an economic commodity and a sexual merchandise which can bring profit. The mass media have been screaming about the proliferation of prostitutes and especially about the increase of child prostitutes in Suva and some outer islands. Prostitutes engage in sexual relation in an impersonal transaction for financial gain. Tis study reveals that some prostitutes fall in love with their regular customers and hope to marry them eventually. The chief interest is the pride for the sex act. The control of prostitution employment has to be regulated and young ones should be trained in skills to be able to have a stable livelihood.

\section{Conclusion}

Women involved in prostitution are perceived as dirty and sinful. 
Citation: Muertigue RR, Gounder S, Naiker K (2018) The Prevalence of Prostitution in Fiji: Its Socio-economic Impact. Arts Social Sci J 9: 318. doi: 10.4172/2151-6200.1000318

Society condemns as women with a very low morale which is a misconception. The concept of morality in Fiji is very strong. Most of these women stay long in their job because they don't have any choice. They are deprived of education and certain basic skills necessary to find a decent and stable job. The influx of tourist visitors in Fiji contributes also to the perpetuation of the prostitutes in the country. Hence, the government of Fiji shall formulate plans, programs and policies to address this societal issue.

\section{References}

1. Harcourt C (2017) Legal Prostitution. Combatting Trafficking in Persons (Ctip) Training Course.

2. Prostitution Probe on-Fiji Times Online.
3. Poverty forcing Young Girls into Prostitution in Fiji (2009).

4. Prostitution law changes Fiji's night life (2017)

5. Leslie AJ (2009) Prostitution as public Nuisance: Prostitution Policy in Canada The Politics of Prostitution, pp: 83-102.

6. Save the Children Fiji undated (2017) The Commercial Sexual Sex Trafficking of children in Fiji - Save The Children Fiji.

7. Fiji's Massage Parlours Operating as Brothels (2017) Social Psychology, General Strain Theory and Prostitution.

8. Struggles in Wageless Life: Sex Worker Organizing (2016) Collective Agency and Autonomous Sex Work.

9. The Socio Economic Factors and Effects of Prostitution (2017). 